\title{
The European Respiratory Society's 10 Principles for Lung Health
}

\author{
Ildikó Horváth ${ }^{1}$, Maeve Barry², Guy Brusselle ${ }^{3}$, Otto Chris Burghuber ${ }^{4}$, \\ Andrew Bush ${ }^{5}$, Carlos Robalo Cordeiro ${ }^{6}$, Mina Gaga $^{7}$, Christina Gratziou ${ }^{8}$, \\ Isabel Saraiva ${ }^{9}$, Daiana Stolz ${ }^{10}$, Thierry Troosters ${ }^{11}$, Tobias Welte $^{12}$, \\ Giovanni Battista Migliori (1) ${ }^{13}$ and Guy Joos ${ }^{3}$
}

Affiliations: 'Semmelweis University, Pulmonology, Budapest, Hungary. ${ }^{2}$ European Respiratory Society, Brussels, Belgium. ${ }^{3}$ Ghent University Hospital, Dept of Respiratory Diseases, Ghent, Belgium. ${ }^{4}$ Otto Wagner Hospital Vienna, Vienna, Austria. ${ }^{5}$ Royal Brompton and Harefield NHS Foundation Trust, London, UK. ${ }^{6}$ University Hospital of Coimbra, Dept of Pulmonology and Allergy, Coimbra, Portugal. ${ }^{7}$ Athens Chest Hospital Sotiria, 7th Respiratory Medicine Dept, Athens, Greece. ${ }^{8}$ Evgenidio Hospital, Smoking Cessation Centre, Athens, Greece. ${ }^{9}$ European Lung Foundation, Sheffield, UK. ${ }^{10}$ University Hospital Basel, Pulmonary Care Division, Basel, Switzerland. ${ }^{11} \mathrm{KU}$ Leuven, Dept of Rehabilitation Sciences, Leuven, Belgium. ${ }^{12}$ University of Hannover, Dept of Respiratory Medicine, Member of the German Center of Lung Research (DZL), Hannover, Germany. ${ }^{13}$ S. Maugeri Foundation, Who Collaborating Centre for TB, Tradate, Italy.

Correspondence: Guy Joos, Ghent University Hospital, Dept of Respiratory Diseases, C. Heymanslaan 10, 9000 Ghent, Belgium. E mail: guy.joosđugent.be

@ERSpublications

With the ERS 10 Principles for Lung Health, @ERSTalk proposes a call to action to improve respiratory health and invites all stakeholders (politicians, policy makers, patients and the public) to support it http://ow.ly/9dW730mkhZu

Cite this article as: Horváth I, Barry M, Brusselle G, et al. The European Respiratory Society's 10 Principles for Lung Health. Eur Respir J 2018; 52: 1801373 [https://doi.org/10.1183/13993003.013732018].

June 2017 saw the annual European Respiratory Society (ERS) Presidential Summit in Ghent, Belgium. Entitled "A public health approach to respiratory health", the summit brought together respiratory specialists and public health voices to discuss what respiratory health now means in terms of public health [1]. In looking at public health and disease prevention, the summit took up themes from the The European Lung White Book [2] with debate centred on public health pyramid for respiratory health [3], while drawing on approaches from other disease areas [4].

It was in these discussions that the foundations of the ERS 10 Principles for Lung Health were set, and in turn developed together with representatives of all specialities of ERS through a roundtable discussion held in February 2018 in Brussels, Belgium. In setting out the ERS 10 Principles for Lung Health, the society proposes a call to action to improve respiratory health, which it invites all stakeholders (politicians, policy makers, patients and the public) to support. The 10 principles are, as such, intended as an advocacy tool for all involved in lung health. This editorial aims to provide a summary of the 10 principles and an overview of the points raised therein.

\section{1) Every breath counts}

Healthy lungs are a cornerstone of human health. Loss of lung function is linked to a worsening of cardiac and other conditions, together with a decrease in life expectancy. Respiratory diseases represent an important public health challenge. On the World Health Organization (WHO) list of the top 10 global causes of death in 2016 [5], chronic obstructive pulmonary disease (COPD) was ranked as the third cause of death followed 
TABLE 1 Aggregated annual direct and indirect costs and the value of disability-adjusted life-years (DALYs) lost for European Union countries 2011 by disease

\begin{tabular}{lcccc} 
& $\begin{array}{c}\text { Direct costs } \\
€ \text { bn }\end{array}$ & $\begin{array}{c}\text { Indirect costs } \\
€ \text { bn }\end{array}$ & $\begin{array}{c}\text { Monetised value of } \\
\text { DALYs lost } € \text { bn }\end{array}$ & $\begin{array}{c}\text { Total costs } \\
€ \text { bn }\end{array}$ \\
\hline COPD & 23.3 & 25.1 & 93.0 & 141.4 \\
Asthma & 19.5 & 14.4 & 38.3 & 72.2 \\
Lung cancer & 3.35 & $\mathrm{NA}$ & 103.0 & 106.4 \\
TB & $0.54^{+}$ & + & 5.37 & 5.9 \\
OSAS & 5.2 & 1.9 & $\mathrm{NA}$ & 7.1 \\
Cystic fibrosis & 0.6 & $\mathrm{NA}$ & $\mathrm{NA}$ & 0.6 \\
Pneumonia/ALRI & 2.5 & $\mathrm{NA}$ & 43.5 & 46.0 \\
Total & 55.0 & 41.4 & 283.2 & 379.6 \\
\hline
\end{tabular}

Data are given in billions (bn) of euros at 2011 values. COPD: chronic obstructive pulmonary disease; TB: tuberculosis; OSAS: obstructive sleep apnoea syndrome; ALRI: acute lower respiratory infections; NA: not available. ": primary care, hospital outpatient and inpatient care, drugs, and oxygen; ": lost production including work absence and early retirement; ${ }^{+}$: indirect costs included with direct costs.

by lower respiratory infections in fourth place, and trachea, bronchus and lung cancer in sixth position, with tuberculosis (TB) coming in 10th. Together, these diseases resulted in $\sim 9$ million deaths worldwide, second only to the combined death toll of ischaemic heart diseases and stroke of 15.2 million.

\section{2) Know the cost to understand the value}

Respiratory diseases place a huge burden on society in terms of disability and premature mortality, and also in direct healthcare costs, drugs prescribed and the indirect costs related to lost productivity (table 1) [6].

\section{3) Work better together}

ERS, through the commitment of its members, plays a leading role in the fight against respiratory disease. Working together within ERS, the potential of members is amplified, and ERS seeks to build on this expertise and success through learning from and working with others beyond the society. Some key examples include: the Finnish Asthma Programme; joint guidelines with the American Thoracic Society on management strategies to prevent and treat exacerbations of COPD [7]; the European initiative for quality management in lung cancer care [8]; the TB consilium in collaboration with the WHO [9]; the European Multicentre Bronchiectasis Audit and Research Collaboration (EMBARC)/Innovative Medicines Initiative on bronchiectasis and related respiratory infections [10]; and the European Commission-supported European Reference Network on Respiratory Diseases Concentrating on Rare Diseases (ERN-LUNG) (https://ern-lung.eu/).

\section{4) Promote lung health}

If we are to promote lung health effectively, then we need to develop legislation and policies to prevent respiratory disease and promote lung health. This means we need to engage in diverse policy areas such as tobacco control [11], smoking cessation, housing, energy, transport, air quality [12], climate change [13] and occupational exposures [14]. Through our dedicated Tobacco Control Committee and Environment and Health Committee, ERS monitors policy developments in these areas and responds to represent the voice of respiratory professionals in order to ensure all policies promote lung health. The ERS, working with WHO and the European Chronic Disease Alliance, has committed itself to having an active role in addressing noncommunicable diseases in order to help to reach the sustainable development goal targets set by the WHO and represent the importance of respiratory health at high-level United Nations meetings.

\section{5) Look again at our health systems}

We need to look again at our healthcare systems to carry out a fitness check. Health systems for respiratory health would ideally include national programmes for the main respiratory diseases but there are many other elements which could be considered. In particular, there is a number of ERS initiatives that could provide support such as the TB Consilium, which could be mirrored for use in other areas, or the use of ERS standardised educational syllabi and curricula to support the harmonisation of training across countries. 


\section{6) Ensure lung health is accessible for all}

The concept of a "heart attack" is universally understood and easily recognised. Less well known is the concept of a "lung attack", a sudden deterioration of the respiratory system associated with symptoms of distress such as shortness of breath. A lung attack requires prompt treatment by invasive or noninvasive assistance tools, such as oxygen therapy, mechanical ventilation or extracorporeal lung supportive devices, which need to be carried out by specialist expert units. Patient outcomes depend hugely on the expertise available and quality of care; the highest level of both must be available for all.

\section{7) Use our voice as patients and professionals}

The strength of ERS lies in the expertise of its $>30000$ members. A key benefit of ERS is that it addresses all respiratory diseases, from the big 5 to the rare diseases, and from prevention to care. This is a sizable community, based on science and education, and allowing for advocacy grounded on the evidence. ERS is a reliable, unbiased partner, and we should not be afraid to use our voice to engage with policy and politics. The European Lung Foundation (ELF) is uniquely placed to ensure that the patient voice is both heard and understood. Each ERS member has the capacity to become a 2-min advocate equipped with a simple message on defined topics with which to engage not only policy makers but also media and the public (table 2). We have the evidence but only in speaking out can we tackle the knowledge-action gap that must be overcome in order to effect change.

\section{8) Make data work for everyone}

To give any benefit to public health and clinical action we need not only enhanced surveillance but also big data along with big infrastructure. Comprehensive disease registries are needed to ensure full epidemiological and clinical population coverage, and equally, much more detailed data collection within "collaborative pan-European centre-based networks". ERS could lead such collection in using Clinical Research Collaborations (CRCs) as tools for monitoring and creating surveillance methodologies to ensure stronger surveillance systems. One such example is EMBARC [10], which was originally established as an ERS CRC with the objectives of developing an international European Bronchiectasis Registry, and bringing clinicians and researchers together to drive improvements in clinical research, clinical care and education.

\section{9) Raise the profile of lung science and education}

ERS has the ambitious task of developing services and educational content for a diverse group of health professionals, all with different health systems, resources, cultures, expectations and local challenges. The educational portfolio of the society is developed by respiratory professionals for respiratory professionals; it works thanks to hundreds of members volunteering to strive to develop scientific and educational projects that serve the community in an independent manner. Being a home for different professional groups and ensuring patient input is taken into consideration in projects and programme developments, ERS expects a better global approach to patients' conditions and aims at best outcomes for patient care. Research and innovation are crucial to our understanding, optimal management and future treatment of respiratory disease. Presently, Europe lacks a strong strategic scientific framework for tackling chronic diseases. We need a scientific platform in Europe to consolidate expertise and resources across borders, providing significant added value [15]. This would address the currently fragmented respiratory research landscape in Europe and help accelerate the translation of discoveries into applications that will impact healthcare delivery in the future. Looking at lung science, we must ensure that respiratory medicine remains an attractive speciality for young researchers and ERS is committed in this regard.

\section{TABLE 2 European Respiratory Society 2-min advocacy}

$\begin{array}{ll}\text { Tobacco } & \begin{array}{l}\text { Effective implementation of the EU Tobacco Products Directive } \\ \text { Regulation of new tobacco products along with continued support for proven smoking cessation programmes } \\ \text { Air quality legislation that sets pollutant limits based on the latest proven scientific evidence on adverse health effects } \\ \text { and recognises the co-benefits in tackling climate change }\end{array} \\ \begin{array}{l}\text { Chronic diseases } \\ \text { A structured, coordinated and funded approach to tackling NCDs including concrete public health measures based on } \\ \text { the WHO "best buys" for risk factor prevention }\end{array} \\ \begin{array}{l}\text { Infectious diseases } \\ \text { An integrated and comprehensive EU framework to improve TB prevention, treatment and care, and the allocation of } \\ \text { adequate funding to research, in particular on multidrug-resistant TB and extensively resistant TB } \\ \text { framework }\end{array} \quad \begin{array}{c}\text { A broad research funding programme with a better convergence between research and clinical needs while keeping a } \\ \text { long-term perspective on biomedical research }\end{array}\end{array}$

EU: European Union; NCD: noncommunicable disease; WHO: World Health Organization; TB: tuberculosis. 


\section{0) Share our success in lung health and innovation}

ERS is a shared community and its added value lies in supporting this community to share their stories. In promoting shared experiences not only in terms of the latest science or clinical practise guidelines but also with respect to personal or career support, ERS can help shape the lung community. The society organises the largest face-to-face event in the respiratory calendar with the annual ERS International Congress that brings together $>20000$ scientists, researchers and healthcare professionals from all over the world. Scientists, clinicians and industry partners share their top successes with each other, policy makers and the media. ERS also has a patient and public-facing voice via the ELF, and our Advocacy and EU Affairs office in Brussels ensures that the need for "lung health in all policies" is communicated to policy makers and opinion leaders. Links to national societies through the Conference of European National Respiratory Societies helps to disseminate policy messages to the local level. Moreover, ERS social media channels target all people interested in lung health. By further investing in these channels, ERS will continue to make sure that globally, the commitment to lung health is met.

We invite all readers to support these 10 Principles for Lung Health and to join us in ensuring that "every breath counts".

The authors sincerely thank all those who contributed to the drafting of the ERS 10 Principles for Lung Health, both those who attended discussions and those who provided written contributions. The full version, including details of all contributors, is available from www.ersnet.org/10PrinciplesforLungHealth.

Conflict of interest: I. Horvath has nothing to disclose. M. Barry is an employee of the European Respiratory Society. G. Brusselle has nothing to disclose. O.C. Burghuber has nothing to disclose. A. Bush has nothing to disclose. C. Robalo Cordeiro has nothing to disclose. M. Gaga reports receiving grants from Novartis, Elpen, GSK and Chiesi, outside the submitted work. C. Gratziou has nothing to disclose. I. Saraiva is Chair of the European Lung Foundation. D. Stolz has nothing to disclose. R. Troosters reports that he is a member of the European Respiratory Society Core Management Group. T. Welte has nothing to disclose. G.B. Migliori has nothing to disclose. G. Joos reports receiving grants, and personal fees for advisory boards and lectures from AstraZeneca and Novartis; grants from Boehringer Ingelheim and Chiesi; grants and personal fees for advisory boards from GlaxoSmithKline; and personal fees for lectures from Teva, outside the submitted work.

\section{References}

1 European Respiratory Society. ERS Presidential Summit 2017. www.ersnet.org/congress-and-events/ ers-presidential-summits/a-public-health-approach-to-respiratory-health. Date last updated: June 2017.

2 Gibson GJ, Loddenkemper R, Sibille Y, et al., eds. The European Lung White Book. 2nd Edn. Sheffield, European Respiratory Society, 2013.

3 European Respiratory Society. ERS Presidential Summit 2017 Materials. https://ers.app.box.com/s/ xhhg5fzoo35gt0ittf5dzvcmrdmbpma8. Date last updated: June 2017.

4 Castellano JM, Narula J, Castillo J, et al. Promoting cardiovascular health worldwide: strategies, challenges, and opportunities. Rev Esp Cardiol (Engl Ed) 2014; 67: 724-730.

5 World Health Organization. Global Health Estimates 2016: Deaths by Cause, Age, Sex, by Country and by Region, 2000-2016. Geneva, WHO, 2018.

6 Gibson GJ, Loddenkemper R, Lundbäck B, et al. Respiratory health and disease in Europe: the new European Lung White Book. Eur Respir J 2013; 42: 559-563.

7 Papi A, Rabe KF, Rigau D, et al. Management of COPD exacerbations: a European Respiratory Society/American Thoracic Society guideline. Eur Respir J 2017; 49: 1600791.

8 Blum TG, Rich A, Baldwin D, et al. The European initiative for quality management in lung cancer care. Eur Respir J 2014; 43: 1254-1277.

9 Blasi F, Dara M, van der Werf MJ, et al. Supporting TB clinicians managing difficult cases: the ERS/WHO Consilium. Eur Respir J 2013; 41: 491-494.

10 Chalmers JD, Aliberti S, Polverino E, et al. The EMBARC European Bronchiectasis Registry: protocol for an international observational study. ERJ Open Res 2015; 1: 00081-2015.

11 Vardavas C, Filippidis FT, Ward B, et al. Plain packaging of tobacco products in the European Union: an EU success story? Eur Respir J 2017; 50: 1701232.

12 Brunekreef B, Künzli N, Pekkanen J, et al. Clean air in Europe: beyond the horizon? Eur Respir J 2015; 45: 7-10.

13 Barry M, Annesi-Maesano I. Ten principles for climate, environment and respiratory health. Eur Respir J 2017; 50: 1701912 .

14 De Matteis S, Heederik D, Burdorf A, et al. Current and new challenges in occupational lung diseases. Eur Respir Rev 2017; 26: 170080.

15 Soriano JB, Paton J, Martin Burrieza F, et al. The ERS Research Agency: the beginning. Eur Respir J 2016; 47: $1017-1023$. 